\title{
Tekrarlanan endoskopi ile geç dönemde saptanabilen özofagusta yabancı cisim
}

\author{
Detectable esophageal foreign body by repeated endoscopy in the late term
}

Nesibe TAŞER ${ }^{1}$, Murat SARIKAYA², Bilal ERGÜL², Zeynal DOĞAN² ${ }^{2}$ Levent FILIK² ${ }^{2}$, Abdullah Ibrahim ÇALIŞIR ${ }^{1}$

Ankara Eğitim ve Araştırma Hastanesi, ${ }^{1}{ }^{1}$ ç Hastalıkları Kliniği,${ }^{2}$ Gastroenteroloji Kliniği, Ankara

Yabancı cisimlerin özofagusa impakte olması önemli morbidite ve mortaliteye neden olabilir. Genellikle çocukluk çağı sorunu olmakla birlikte erişkinlerde de karşılaşllabilmektedir. Bu olgu sunumunda, ilk endoskopik incelemede saptanamayan özofagustaki kemiğin ancak 10 gün sonraki kontrol endoskopisinde görülerek başarılı bir şekilde çıkarılışını sunuyoruz. Özofagusa impakte yabancı cisimlerin tanısı her zaman kolay olmayabilir. Bu nedenle endoskopik incelemenin en ideal şartlarda yapılması gerekirse kontrol endoskopisinin gerçekleştirilmesi önemlidir.

Anahtar kelimeler: Özofagusta yabancı cisim, disfaji, özofagusta ülser

\section{GİRİş}

Yabancı cisim yutulması gastroenteroloji kliniğinde sıkça karşılaşılan problemler arasında yer almaktadır. Çocukluk çağında daha sık görülmesine rağmen erişkin yaş grubunda da ciddi komplikasyonlara neden olabilmektedir. ABD'de her yıl yaklaşık 1500 kişi yabancı cisim yutulmasına bağlı komplikasyonlar nedeniyle hayatını kaybetmektedir. Yabancı cisimler gastrointestinal sistemdeki en dar bölge özofagus olması nedeniyle sıklıkla bu bölgede saptanır. Yutulan yabancı cisimlerin büyük bir çoğunluğu gastrointestinal traktan kendiliğinden geçebilirken, yaklaşık \%10-20 kadarı cerrahi olmayan endoskopik girişimler ile acil müdahaleyi gerektiren vakalardır (1-3). Hastalarda çoğunlukla ağrılı yutma veya takılma hissi olur ve vakaların büyük bir kısmı ilk 12 saat içinde hastaneye başvurur (4). Burada 10 gün önce yemek yerken tavuk kemiğini yanlışlıkla yutan ve aynı gün başka bir merkezde endoskopisi yapılmış olan ancak boğazda takılma hissi ve göğsünde ağrı şikayeti devam eden bir vakayı sunuyoruz.

\section{OLGU}

Kırk dört yaşında erkek hasta yaklaşık 10 gün önce akşam yemeğinde yanlışlıkla tavuk kemiği yutmuş. Boğazda takılma hissi ve gögüs ağrısı olan hastaya başvurduğu merkezde gastroenterolog tarafından üst gastrointestinal sistem endoskopisi yapılmış. Hastanın endoskopi raporunda özofagus üst uçta ülser ve gıda artığı olduğu belirtilerek hastaya proton pompa inhibitörü (PPI) ve sükralfat tedavisi başlanmış. Yaklaşık 10 gündür tedavisini almasına rağmen şikayetleri artan hasta
Foreign body impaction in the esophagus can cause significant morbidity and mortality. Although it is generally accepted as a childhood problem, it can also be seen in adults. Herein, we present an adult patient who had swallowed a chicken bone. The impacted bone in the esophagus was not detected in the first endoscopic examination. The chicken bone was removed successfully under endoscopic control 10 days later. This case presentation shows that a first examination may fail to detect a foreign body in the esophagus, thus necessitating a second endoscopy.

Keywords: Esophageal foreign body, dysphagia, esophageal ulcer

gastroenteroloji polikliniğimize başvurdu. Hastanın endoskopisi yapıldı. Özofagus üst uçta mukozaya impakte olan ve ülsere neden olmuş tavuk kemiği görüldü (Resim 1). Dişli yabancı cisim forsepsi ile üst ucundan yakalanarak çıkartıldı (Resim 2). Kemiğin impakte olduğu bölge endoskopi ile kontrol edildiğinde derin ülser saptandı (Resim 3). Hastanın yapilan radyolojik incelemelerinde perforasyon saptanmadi. Hastanın mevcut tedavisine devam edildi. Kontrol endoskopisinde ülserin iyileşmeye başladığı görüldü.

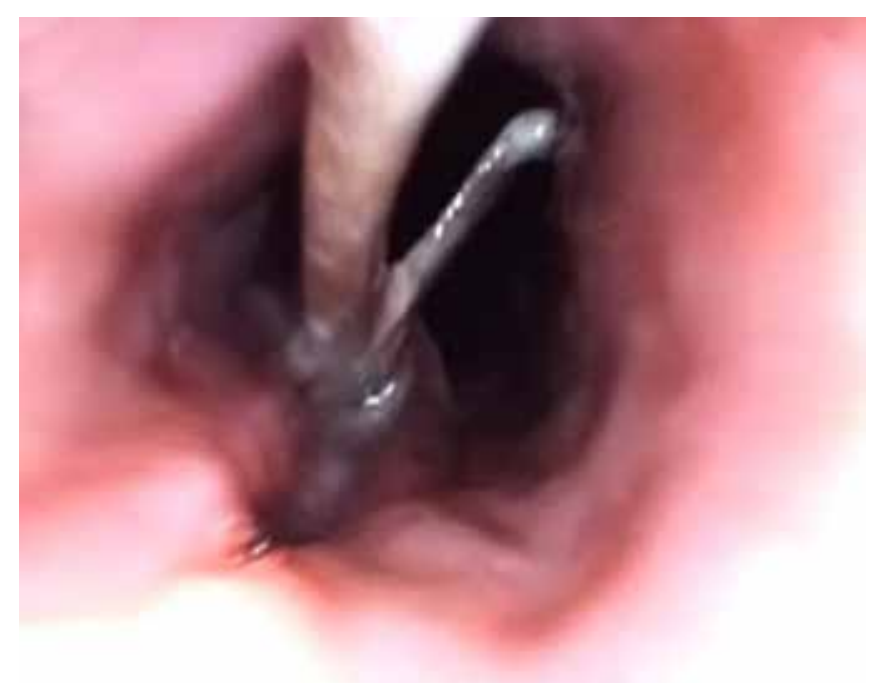

Resim 1. Özofagusa impakte olan tavuk kemiği. 


\section{TARTIŞMA}

Özofageal yabancı cisimlere yaklaşım yutulan cismin tipine, hastanın semptomlarına ve klinik durumuna bağlıdır. Çoğu yabancı cisimler düz grafi ile saptanabilirken balık kılçığı gibi bazı yabancı cisimler ise grafide görülemeyebilir. Hasta yabancı cisim yuttuğundan şüheleniyor ve semptomları da varsa grafide yabancı cisim görülmese bile endoskopi yapılmalıdır. Vakaların yaklaşık \%80'inde yabancı cisim gastrointestinal traktustan sorunsuz olarak geçer. Yaklaşık \%20 vakada endoskopi ve \%l'den az vakada da cerrahi uygulanması gerekir. Özellikle özofageal perforasyon ve komşu damarlarda hasar gibi komplikasyonlar olması durumunda cerrahi girişim gerekebilir (5). Özofageal yabancı cisimler 24 saatten daha uzun süre impakte olarak kaldığı zaman özofageal perforasyon, aorto-özofageal fistül ve mediastinal apse gibi komplikasyonlara neden olabilmektedir. Oluşan mukozal ödem veya yüzeyel ülser ile çevrili yara bölgesi yabancı cismin endoskopik olarak alınmasını engelleyebilir (6).

Yabancı cisimlerin büyük bir kısmı endoskopik olarak başa-

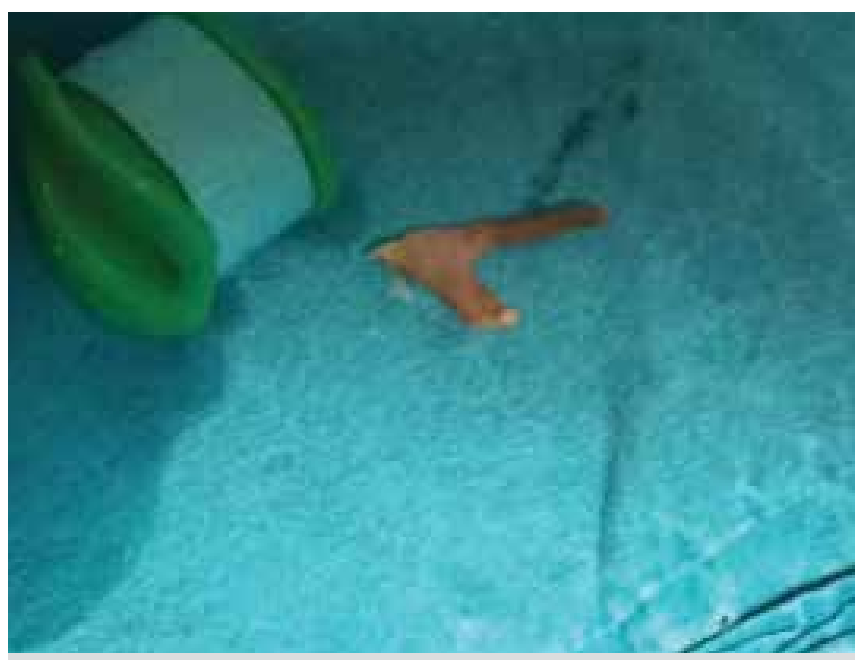

Resim 2. Endoskopik olarak çlkarılan tavuk kemiği.

\section{KAYNAKLAR}

1. Llompart A, Reyes J, Ginard D, et al. Endoscopic management of foreign bodies in the esophagus. Results of a retrospective series of 501 cases. Gastroenterol Hepatol 2002;25:448-51.

2. Ayantunde AA, Oke T. A review of gastrointestinal foreign bodies. Int J Clin Pract 2006;60:735-9.

3. Block B, Schachschal G, Schmidt H. Endoscopy of the upper GI tract: Atraining manual. Accessed June 15, 2010

4. Ergül B, Filik L, Doğan Z, Bıyıkoğlu 1. Özofagusta geç dönemde saptanarak endoskopik olarak çıkarılan yabancı cisim. Gastrointestinal Endoskopi 2012;20:25-6 rılı bir şekilde çıkarılabilmektedir Endoskopi yeterli sedasyon veya genel anestezi altında yapılırsa \%5'lik komplikasyon oranıyla birlikte \%90'dan fazla başarı sağlar (7). Bazı merkezlerde endoskopun hastaya yutturulması işlemi yardımcı sağlık personeli tarafından yapılmaktadır. Bu gibi durumlarda özofagusun en dar yeri olan faringoözofageal sfinkter ve distali hızlı geçilebileceği için bu bölgedeki lezyonlar kolayca atlanabilir.

Sedasyon uygulanmadan yapılan işlemlerde özellikle de özofagusta yabancı cisim bulunması gibi hastanın işleme toleransını azaltan durumlarda işlem hasta tarafindan tolere edilememektedir. Bu durum endoskopistin özofagustan hızlı çıkmasına ve olası lezyonların atlanmasına neden olabilir. Sonuç olarak özellikle yabancı cisim çıkarılması gibi özellik arz eden durumlar başta olmak üzere endoskopi yeterli sedasyon uygulanarak yapılmalı ve tüm bölgeler net olarak değerlendirildikten sonra işlem sonlandırılmalıdır. Aksi durumda hayati riske sahip komplikasyonlara neden olabilecek durumlar atlanabilir.

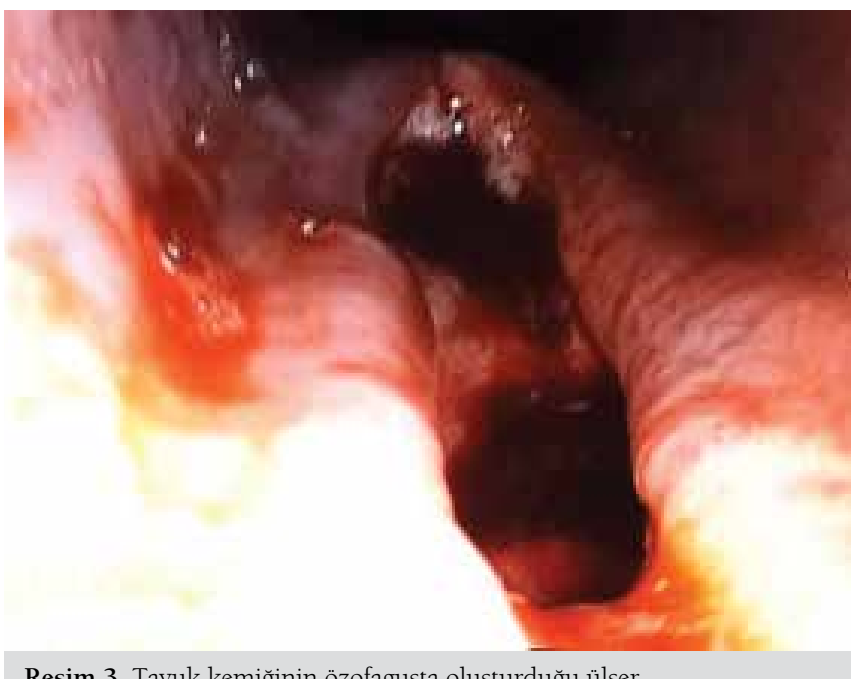

Resim 3. Tavuk kemiğinin özofagusta olușturduğu ülser.

5. Ambe P, Weber SA, Schauer M, Knoefel WT. Swallowed foreign bodies in adults. Dtsch Arztebl Int 2012;109:869-75.

6. Li ZS, Sun ZX, Zou DW, et al. Endoscopic management of foreign bodies in the upper-GI tract: experience with 1088 cases in China. Gastrointest Endosc 2006;64:485-92.

7. Triadafilopoulos G, Roorda A, Akiyama J. Update on foreign bodies in the esophagus: diagnosis and management. Curr Gastroenterol Rep 2013;15:317. 